\title{
The Effect of Processing Method on Fortified Rice Noodle Quality and Fortificant Retention
}

\author{
Nura Malahayati ${ }^{* *}$, Kharidah Muhammad², Jamilah Bakar ${ }^{3}$, Roselina Karim ${ }^{3}$ \\ ${ }^{1}$ Department of Agricultural Technology, Faculty of Agriculture, Sriwijaya University, Indonesia \\ ${ }^{2}$ UPM-BERNAS Research Laboratory, Faculty of Food Science and Technology, Universiti Putra Malaysia, Malaysia \\ ${ }^{3}$ Department of Food Technology, Faculty of Food Science and Technology, Universiti Putra Malaysia, Malaysia
}

*Corresponding author: Nura Malahayati, Department of Agricultural Technology, Faculty of Agriculture, Sriwijaya University, 30662 Ogan Ilir, South Sumatera, Indonesia, Tel: +62815-3837945; Fax: +62711-580664;

E-mail: nura_malahayati@yahoo.com

\begin{abstract}
Rice noodle, a widely consumed rice product in Southeast Asia, is potentially carrier for fortification with vitamin A, folic acid and iron. However, processing method is one of the main factors that may affect the quality of fortified rice noodle and retention of fortified micronutrients or fortificants in the noodle. The aims of this study were to examine chemical properties, quality, microstructure and sensory characteristics of fortified rice noodle which was prepared by two different processing methods, boiling and steaming. The retention of vitamin A, folic acid and iron at each stage of rice noodle processing was also investigated. Steaming enhanced the chemical properties, quality, microstructure and panelists preferences of rice noodle. The patterns of vitamin A, folic acid and iron retentions in rice noodle prepared by the two different processing methods were very similar at each stages of processing. However, vitamin A, folic acid and iron retentions at each stage of processing were significantly higher $(p<0.05)$ in rice noodle prepared by steaming than those in rice noodle prepared by boiling. Boiling retained $16.12 \%$ vitamin A, 35.08\% folic acid and $86.46 \%$ iron while steaming retained $23.51 \%$ vitamin A, $48.75 \%$ folic acid and $99.34 \%$ iron.
\end{abstract}

Received Date: December 20, 2016

Accepted Date: March 23, 2017

Published Date: March 27, 2017

Citation: Malahayati, N., et al. The Effect of Processing Method on Fortified Rice Noodle Quality and Fortificant Retention. (2017) Int J Food Nutr Sci 4(2): 30- 37 .

DOI: $10.15436 / 2377-0619.17 .1279$

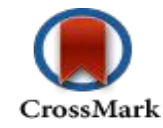

Keywords: Fortificant retention; Processing method; Quality; Rice noodle

\section{Introduction}

Despite its wide consumption by the world population, polished rice is proven to be related to micronutrient deficiency among people in rice consuming countries, particularly vitamin A, folic acid, and iron deficiencies. Children and women of childbearing age are the most vulnerable segment to these micronutrient deficiencies. Adequate intake and availability of these dietary essential vitamins and minerals are closely related to the survival, physical and mental development, and the overall well-being of individuals.

Food fortification is one of the strategies to combat micronutrient deficiencies. This strategy is technologically and economically effective for increasing micronutrient intakes in human population ${ }^{[1]}$ and it is the most practical and long-term approach $^{[2]}$. Multiple fortification of several types of food in- cluding beverages ${ }^{[3]}$, salt $^{[4]}$, Ultra rice ${ }^{[[]}$, and whole wheat flour ${ }^{[6]}$ are gaining popularity to overcome micronutrient malnutrition in developing countries. In addition, the food consumed by most population segments, ideally, should be chosen as a vehicle.

Fortifying rice or rice products with deficient micronutrients is one of the strategies to overcome the deficiencies. Rice noodle, made from rice flour, is the main processed food product widely consumed in Southeast Asia. Rice noodle may be sold as a fresh product or they may be dried prior to packaging. Consumption of rice noodle fortified with multiple fortificants (vitamin A, folic acid and iron) may contribute in reducing the micronutrient deficiencies in developing countries, particularly in Southeast Asia.

In order to make any fortification program a success, it is important to monitor physicochemical changes that take place in the food vehicle and the end product as a result of fortifica- 
tion. Quality is one aspect that needs to be considered in fortified rice noodle production. Both cooking and textural qualities were found to influence the consumers' acceptance towards the produced rice noodle ${ }^{[7-11]}$. In addition, the retention of fortified micronutrients is another crucial factor that determines the quality of fortified food products ${ }^{[12]}$.

The domestic and small-scale production of rice noodles has long been widespread in rice-producing countries. The process used were varied from one region to another, to which were all based on the conventional ways which were linked to local traditions and also as a function of the particular qualities of the local types of rice. The common practice of producing rice noodle in the food industry is by boiling extruded rice dough which has been incorporated with a binding agent such as tapioca, maize or sago starch to improve textural quality of rice noo$\mathrm{dle}^{[13]}$. However, this method was costly, time consuming and no micronutrient retention study has been done. In earlier study, we found that rice noodle produced from flour with particle size $\leq 63 \mu \mathrm{m}$ had an improvement in cooking and textural qualities, sensory properties, and retention of fortificants ${ }^{[14]}$. In this study, we applied similar fortified rice flour with particle size $\leq 63 \mu \mathrm{m}$ to prepare the rice noodle and no binding agent was employed as it was replaced by flour particle size reduction.

The objective of this study therefore was to compare the effect of two processing methods on the chemical composition, cooking quality, microstructure, texture, sensory properties and fortificant retention of rice noodle.

\section{Materials and Methods}

\section{Source of materials}

Malaysian rice used for this study was obtained from a local supermarket in Serdang, Selangor State, Malaysia. The variety used was MR 219. Dry blended premix containing vitamin A, folic acid and iron (FT091283AP) was procured from Fortitech Asia Pacific Sdn Bhd, Malaysia used as a fortificant for the rice flour.

Preparation of fortified rice flour: Rice grains were drymilled using a rice miller (Good and Well, Malaysia) with a 200 $\mu \mathrm{m}$ sieve. Rice flour sample was placed in a sieving machine (Fritsch Analysette 3, Germany) with $200 \mathrm{~mm}$ diameter sieves of particle sizes $\leq 63 \mu \mathrm{m}$. Rice flour sample was fortified with a dry blended premix containing vitamin A, folic acid and iron (FT091283AP; Fortitech Asia Pacific Sdn Bhd, Malaysia) at the level of $300 \mu \mathrm{g}$ of vitamin A, $16 \mu \mathrm{g}$ of folic acid, and $42 \mathrm{ppm}$ of iron based on Malaysian Food Regulation ${ }^{[15]}$. Rice flour and premix were mixed by shaking evenly in a closed plastic bottle for $30 \mathrm{~min}$. The fortified rice flour samples were packed in airtight plastic bags and stored at $4^{\circ} \mathrm{C}$ until used. The chemical composition of rice flour sample was the following: moisture content $=8.58 \pm 0.01 \%$, ash content $=0.48 \pm 0.09 \%$, protein content $=$ $7.37 \pm 0.06 \%$, fat content $=0.67 \pm 0.00 \%$, and amylase content $=23.14 \pm 0.08 \%$.

Preparation of fortified rice noodle: The processing of rice noodle in the laboratory was adopted from the practices of Malaysian home industries with some modifications. All the steps in the preparation of the fortified rice noodles were carried out in subdued lighting condition in order to minimize light destruc- tion of the fortificants. Fortified rice flour was mixed with boiled water. The amount of boiled water added was $60 \%$ of the total weight of the dough formed. The mixture was kneaded until the dough was well homogenized. The kneaded dough was extruded through the holes ( $3 \mathrm{~mm}$ in diameter) of a cylindrical shaped mould. The extruded dough was further processed by either of the two types of noodle processing methods: (a) boiled in water until it floats $(10 \mathrm{~min})$ followed by cooling in cold water (4 to $5^{\circ} \mathrm{C}$ ) for $10 \mathrm{sec}$ and strained, (b) steamed for $30 \mathrm{~min}$ until the surface and structure of noodle firms followed by blanching in hot water $\left(98\right.$ to $\left.100^{\circ} \mathrm{C}\right)$ for $10 \mathrm{sec}$ and strained. The former aforementioned process was termed as process $\mathrm{A}$ and the later process B. Fresh rice noodles (RN) prepared using process A was then identified as $\mathrm{RN}-\mathrm{A}$ while fresh rice noodle undergoing process $\mathrm{B}$ was identified as $\mathrm{RN}-\mathrm{B}$. A portion of $\mathrm{RN}-\mathrm{A}$ and $\mathrm{RN}-\mathrm{B}$ were dried at $40^{\circ} \mathrm{C}$ until $10 \%-12 \%$ of final moisture was achieved (about $12 \mathrm{hr}$ ) which were then termed as DRN-A and DRN-B. Then, a portion of DRN-A and DRN-B were cooked (boiled) for $10 \mathrm{~min}$ become CRN-A and CRN-B.

\section{Determination of starch gelatinization degree}

The starch gelatinization degree of RN-A and RN-B was measured according to Birch and Priestley method ${ }^{[16]}$. The $\mathrm{RN}-\mathrm{A}$ and $\mathrm{RN}-\mathrm{B}$ were dried in an oven at $58^{\circ} \mathrm{C}$ and ground through a $200 \mu \mathrm{m}$ sieve. The sample $(0.2 \mathrm{~g})$ was mixed with 98 $\mathrm{mL}$ of distilled water and $2.0 \mathrm{~mL}$ of $10 \mathrm{M}$ potassium hydroxide and vortexed for $5 \mathrm{~min}$ prior to centrifugation at $3000 \mathrm{rpm}$ for $15 \mathrm{~min}$. The supernatant $(1.0 \mathrm{~mL})$ was pipette into test tube and added with $0.4 \mathrm{~mL}$ of $0.5 \mathrm{M}$ hydrochloric acid followed by 10 $\mathrm{mL}$ of distilled water and $0.1 \mathrm{~mL}$ of iodine solution. The mixture was homogenized and its absorbance was then measured using a UV-Vis spectrophotometer (Perkin10 Elmer, USA) at $600 \mathrm{~nm}$. Standard starch solutions were prepared in the same manners as the sample described to obtain a standard curve that can be used to calculate the degree of gelatinization of samples.

\section{Determination of selected chemical compositions}

The ash and moisture contents of DRN-A and DRN-B were determined using the AOAC methods 923.03 and 925.10, respectively. Total fat of the noodles was determined with FOSS Soxtec Automated System 2050 (FOSS, Sweden) which complied with AOAC method 920.85. Total protein was determined using Kjeldahl method based on AOAC method $920.87^{[17]}$.

\section{Determination of the cooking and textural qualities}

Cooking quality of rice noodle was determined using AACC International Approved Method 66 - 50 ${ }^{[18]}$. Rice noodle $(5.0 \mathrm{~g})$ was cut into small pieces $(2.0 \mathrm{~cm}$ in length) and boiled in $60 \mathrm{~mL}$ water until completely cooked $(10 \mathrm{~min})$. The cooked samples were washed in $20 \mathrm{~mL}$ distilled water, drained for 5 min, and weighed immediately. The cooking water was collected and transferred to a Petri dish and dried at $105^{\circ} \mathrm{C}$ to a constant weight. Total cooking loss was calculated based on the dry weight of noodle. The rehydration was calculated as the percentage increase in weight of the cooked noodle compared to the weight of dried noodle.

The cooked noodle was kept in a covered Petri dish for texture analysis within 15 min of cooking, using Stable Micro Systems TA-XT plus texture analyzer (Godalming, UK). Texture profile analysis (TPA) of cooked noodle was determined us- 
ing Bhattacharya et al. method ${ }^{[8]}$. A strand of cooked noodle with $3.5 \mathrm{~mm}$ thickness was compressed by a cylinder probe $(35.0 \mathrm{~mm}$ diameter) until the deformation reached $75 \%$ at a speed of 1.0 $\mathrm{mm} / \mathrm{s}$. The pause between the first and the second compressions was 0.5 second. From the force-time curve of the texture profile, textural properties including hardness, adhesiveness, springiness, cohesiveness, and chewiness were obtained. Ten measurements were made for each sample.

\section{Sensory evaluation}

Sensory evaluation of rice noodle samples $(\mathrm{CRN})$ prepared by the two different processing methods was carried out in the sensory laboratory. Panelists were required to evaluate whether CRN-B was preferred over the CRN-A using paired preference test according to Lawless and Heymann method ${ }^{[19]}$. Sensory properties evaluated was overall acceptability (aroma, appearance, taste and texture). The test is one-sided as the CRN-B was developed to be more on overall acceptability in response to panelists. A group of 50 panelists comprising of students and staffs in Faculty of Food Science and Technology, University Putra Malaysia who were familiar with rice noodle were involved in evaluation. They received the two samples (CRN-A and CRN-B) in simultaneous presentation, half in the order CRN-A and CRN-B, the other half CRN-B and CRN-A. All samples are coded with three-digit random numbers. Panelists are encouraged to make a choice. The null hypothesis is $\mathrm{H} 0$ : the preference for the better overall acceptability (aroma, appearance, taste and texture) CRN-B $\leq 50 \%$. The alternative hypothesis is $\mathrm{Ha}$ : the preference for the $\mathrm{CRN}-\mathrm{B}>50 \%$.

\section{Microstructure observation}

Rice noodle samples (DRN and CRN) were cut into $0.5 \mathrm{~cm}$ pieces and lyophilized. The lyophilized samples were cut into 1 to $2 \mathrm{~mm}$ length, mounted on stubs with double-sided tape and sputter-coated with gold using sputter coater (BAL-TEC SCD005, Liechtenstein, and the Netherlands). The specimens were examined using scanning electron microscope (Philips XL30 ESEM series D6929, Eindhoven, the Netherlands) at the accelerating voltage of $10 \mathrm{kV}$. The surface and cross-section of DRN and CRN were observed at different magnifications.

\section{Determination of vitamin A}

Vitamin A as retinol contents of rice noodle samples was determined using a HPLC (Agilent Technologies, 1200 series, USA) according to AACC International Approved Method $86-06^{[18]}$.

\section{Determination of folic acid}

Folic acid contents of rice noodle samples was determined using HPLC (Agilent Technologies, 1200 series, USA) according to Alaburda et al. Method ${ }^{[20]}$. Five grams of rice noodle samples were extracted with $50 \mathrm{~mL}$ of extraction tetraborate-TCA buffer $\mathrm{pH} 8.5$. The mixture was sonicated for $30 \mathrm{~min}$ in an ultrasonic bath (Branson DTH-5510, USA) and centrifuged at $3500 \mathrm{rpm}$ for $5 \mathrm{~min}$. The supernatant was purified through a strong anionic exchange (SAX, $500 \mathrm{mg} / 3 \mathrm{~mL}$ ) cartridge which was conditioned with $5 \mathrm{~mL}$ of methanol followed by $5 \mathrm{~mL}$ of water, before applying the sample. An analytical aliquot of 2.5 $\mathrm{mL}$ supernatant was transferred to the cartridge. The vacuum was adjusted to elude the sample at about $0.5 \mathrm{drop} / \mathrm{sec}$. When the entire extract was eluted, the column was rinsed with $5 \mathrm{~mL}$ of water and completely drained after the last washing step. Folic acid was eluted with acetate-phosphate buffer ( $\mathrm{pH} 4.5$ ) directly into a $5 \mathrm{~mL}$ volumetric flask. The elude was filtered through a $0.45 \mu \mathrm{m}$ nylon membrane (Advantec MFS, Inc.) and then quantities using HPLC at $280 \mathrm{~nm}$ of UV detection.

To prepare a calibration curve, folic acid (Sigma Aldrich, USA) stock standard solution was prepared by dissolution in $0.1 \mathrm{~mol} / \mathrm{L}$ of sodium hydroxyl. Then, appropriate volumes of the stock solution were diluted with acetate-phosphate buffer. Standard solution and sample volumes of $100 \mu \mathrm{L}$ were injected in triplicate. The linearity was determined in the range of $6-600$ $\mathrm{ng} / \mathrm{mL}$ folic acid using 10 calibrators. For quantitative determination of folic acid peak areas of the sample, chromatograms were correlated with the concentrations according to the calibration curve.

\section{Determination of iron}

Iron (elemental iron) content of rice noodle samples was determined using an atomic absorption spectrophotometer (AAS) (Perkin Elmer, AA400, Shelton, USA) according to AACC International Approved Method 40-70 ${ }^{[18]}$.

\section{Statistical analysis}

Rice noodle production and all determinations reported in this study were performed in triplicate. Data were subjected to analysis of variance (ANOVA) followed by Fisher's least significant difference test (LSD) to compare treatment means; differences were considered at significant level of $95 \%(\mathrm{p}<0.05)$ by using SPSS version 19 software.

\section{Results and Discussion}

\section{Effect of noodle processing method on chemical properties of rice noodle}

The chemical properties of rice noodle prepared by the two different processing methods are shown in (Table 1). Starch gelatinization degree of RN-B was significantly higher than that of RN-A ( $p<0.05)$. This can be attributed to the longer cooking time and blanching process required during $\mathrm{RN}-\mathrm{B}$ preparation subjecting the rice noodle to a higher degree of thermal treatment, resulting in the higher amount of gelatinized starch than that in RN-A.

Moisture content of DRN-B was significantly lower than that of DRN-A. This must be due to the steaming followed by the blanching process resulting in lower water absorption compared to that occurring in the boiling process which was followed by cooling in cold water. Inversely, protein, fat, and ash contents of DRN-B were significantly higher than that of DRN-A ( $p<0.05)$. This was due to leaching of intact starch granules and water soluble nutrients into the surrounding water during RN-A preparation. This result is consistent with the fact that noodle heated in the presence of water (boiling) undergoes an irreversible order-disorder transition (gelatinization) with various changes including starch granule swelling, water retention, loss of crystalline, and leaching amylose $\mathrm{e}^{[21]}$.

Tabel 1: Chemical properties of rice noodle prepared by two different noodle processing methods. 
Fortified Rice Noodle Quality and Fortificant Retention

\begin{tabular}{|l|c|c|}
\hline \hline \multirow{2}{*}{ Rice noodle quality } & \multicolumn{2}{|c|}{ Rice noodle prepared by } \\
\cline { 2 - 3 } & Process A & Process B \\
\hline $\begin{array}{l}\text { Starch gelatinization } \\
\text { degree (\%) }\end{array}$ & $95.95^{\mathrm{a}} \pm 0.04$ & $98.78^{\mathrm{b}} \pm 0.09$ \\
\hline Moisture (\%) & $11.89^{\mathrm{a}} \pm 0.27$ & $11.12^{\mathrm{b}} \pm 0.23$ \\
\hline Protein (\%) & $6.47^{\mathrm{a}} \pm 0.13$ & $6.95^{\mathrm{b}} \pm 0.21$ \\
\hline Fat (\%) & $0.04^{\mathrm{a}} \pm 0.01$ & $0.05^{\mathrm{b}} \pm 0.01$ \\
\hline Ash (\%) & $0.40^{\mathrm{a}} \pm 0.03$ & $0.54^{\mathrm{b}} \pm 0.01$ \\
\hline
\end{tabular}

Note: Data are presented as mean \pm standard deviation of triplicate determinations.

Means for each characteristic followed by the same superscript within the same row are not significantly different at $p<0.05$ by LSD test.

Process A: boiling for 10 min followed by cooling in cold water (4 to $5^{\circ} \mathrm{C}$ ) for $10 \mathrm{sec}$.

Process B: steaming for 30 min followed by blanching in hot water $(98$ to $100^{\circ} \mathrm{C}$ ) for $10 \mathrm{sec}$.

\section{Effect of noodle processing method on the noodle quality}

Cooking and textural qualities of rice noodle are affected by noodle processing method are shown in (Table 2). The optimal cooking time for both DRN-A and DRN-B were $10 \mathrm{~min}$ (Table 2). Cooking loss and rehydration of DRN-B were significantly lower $(\mathrm{p}<0.05)$ than that of DRN-A. This might be due to starch gelatinization degree of RN-B was significantly higher than that of RN-A resulting in the higher amount of gelatinized starch, which in turn reflected on lower solubility of starch and higher cooking tolerance of DRN-B than that of DRN-A. The acceptable level of cooking loss for starchy noodle is below $10 \%{ }^{[22]}$. In this study, the cooking loss for DRN-A and DRN-B were $6.29 \pm 0.98 \%$ and $5.11 \pm 0.32 \%$, respectively, which were well within the acceptable level of cooking loss for starchy noodles.

Tabel 2: Cooking and textural quality of rice noodle prepared by two different noodle processing methods.

\begin{tabular}{|l|c|c|}
\hline \multirow{2}{*}{ Rice noodle quality } & \multicolumn{2}{|c|}{ Rice noodle prepared by } \\
\cline { 2 - 3 } & Process A & Process B \\
\hline Cooking quality: & \multicolumn{2}{|c|}{} \\
\hline Cooking time (min) & $10.0^{\mathrm{a}} \pm 0.12$ & $10.0^{\mathrm{a}} \pm 0.29$ \\
\hline Cooking loss (\%) & $6.29^{\mathrm{a}} \pm 0.98$ & $5.11^{\mathrm{b}} \pm 0.32$ \\
\hline Rehydration (\%) & $322.28^{\mathrm{a}} \pm 20.13$ & $277.71^{\mathrm{b}} \pm 11.16$ \\
\hline Textural quality: & \\
\hline Hardness (g) & $2127.20^{\mathrm{a}} \pm 19.73$ & $2582.93^{\mathrm{b}} \pm 45.27$ \\
\hline Adhesiveness (gs) & $60.92^{\mathrm{a}} \pm 0.02$ & $40.67^{\mathrm{b}} \pm 0.02$ \\
\hline Springiness & $0.71^{\mathrm{a}} \pm 0.08$ & $0.77^{\mathrm{b}} \pm 0.11$ \\
\hline Cohesiveness & $0.48^{\mathrm{a}} \pm 0.05$ & $0.44^{\mathrm{b}} \pm 0.05$ \\
\hline Chewiness (gmm) & $740.47^{\mathrm{a}} \pm 18.08$ & $926.67^{\mathrm{b}} \pm 28.37$ \\
\hline
\end{tabular}

Note: Data are presented as mean \pm standard deviation of triplicate determinations.

Means for each characteristic followed by the same superscript within the same row are not significantly different at $\mathrm{p}<0.05$ by LSD test.

Process A: boiling for 10 min followed by cooling in cold water (4 to $5^{\circ} \mathrm{C}$ ) for $10 \mathrm{sec}$.

Process B: steaming for 30 min followed by blanching in hot water (98 to $100^{\circ} \mathrm{C}$ ) for $10 \mathrm{sec}$.

Textural properties of the rice noodle were also affected by the noodle processing method. CRN-B was harder, more springy, and chewy but less adhesive and cohesive than those of CRN-A ( $\mathrm{p}<0.05)$. This indicated that CRN-B noodle feels less sticky in the mouth, harder and coarser in texture, representing better quality. The fact that RN-B had a higher amount of gelatinized starch must have caused it to have lower starch solubility and lower water holding capacity than those in RN-A. This result was supported by the findings by Juliano and Sakurai ${ }^{[23]}$ who concluded that the amount of gelatinized starch is important for rice noodle structure by acting as a binder during extrusion. This study confirms that higher gelatinized starch improves cooking and textural qualities of rice noodle.

\section{Sensory evaluation of rice noodle}

Results of sensory evaluation based on overall acceptability of CRN-A and CRN-B showed that 36 panelists preferred the CRN-B. Based on the minimum value (X) required for significant preference ${ }^{[19]}$, the value for 50 panelists at an alpha of $5 \%$ was 33 . The obtained value of 36 was greater than the minimum value required and therefore, the panelists had a significant preference for the CRN-B over the CRN-A.

\section{Microstructures of rice noodles prepared by two different noodle processing methods}

Microstructures of RN, DRN and CRN were affected by the noodle processing method as shown in (Figure 1,2,3), respectively. The cross-section of RN-A exhibited a compact structure with some small empty holes (Figure 1A). Furthermore, the RN-B exhibited a regular, smooth and close structure (Figure 1B). This result was consistent with the finding that RN-B had more gelatinized starch than RN-A. Such a structure of RN-B can cause less oxygen diffusion and therefore, may result in less fortificant degradation.
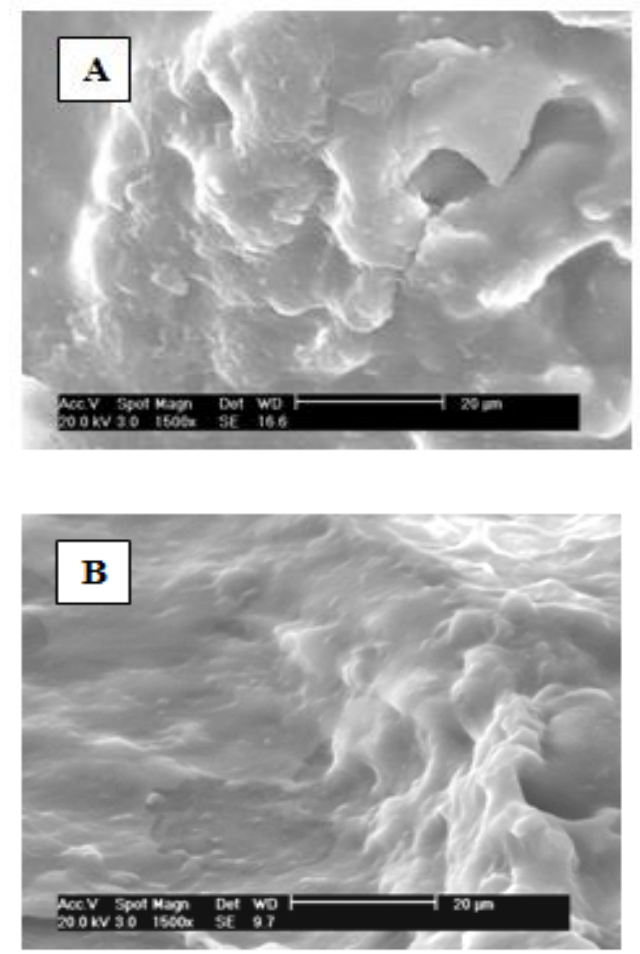

Figure 1: Cross-sections of fresh rice noodle $(\mathrm{RN})$ prepared by two different. noodle processing methods.

(A) RN-A, (B) RN-B at X1500 magnification.

Starch gelatinization in RN influenced the network formation of bonded swollen starch granules present in the porous 
structure of DRN. The higher proportion of gelatinized starch in RN-B resulted in less porousness of DRN-B (Figure 2B) than DRN-A (Figure 2A).
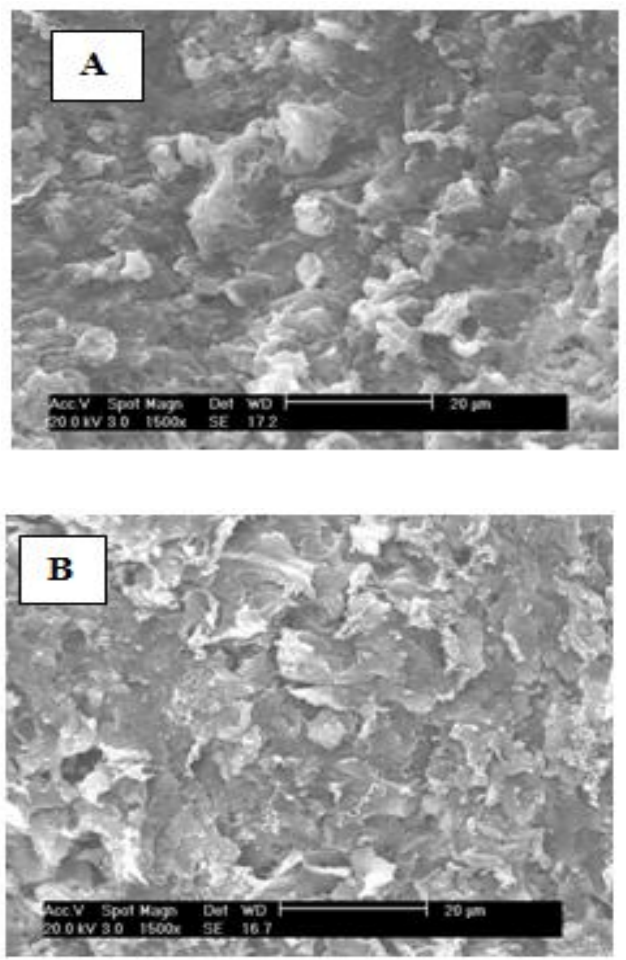

Figure 2: Cross-sections of dried rice noodle (DRN) prepared by two different noodle processing methods.

(A) DRN-A, (B) DRN-B at X1500 magnification.
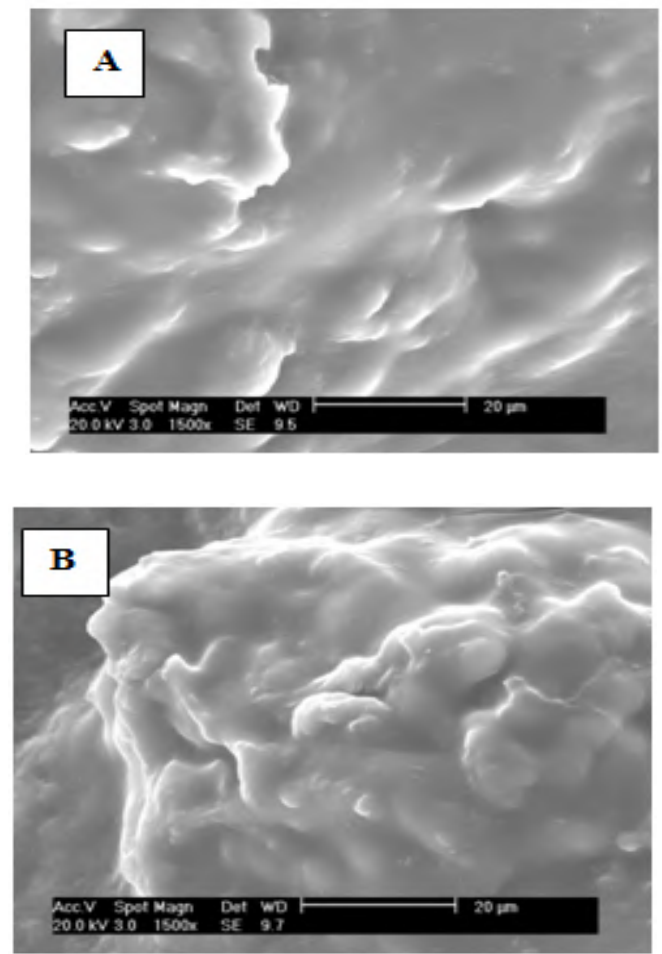

Figure 3: Cross-section of cooked rice noodle (CRN) prepared by two different noodle processing methods.

(A) CRN-A, (B) CRN-B at X1500 magnification.

After cooking, the cross-sections of CRN-A and CRN-B exhibited completely gelatinized rice noodle struc- tures with visible swollen starch network. The cross-section of CRN-B exhibited a more regular, smoother and intact structure (Figure 3B) than that of CRN-A (Figure 3A). This may be due to less leaching of starch occurring during cooking of CRN-B. This result was consistent with the finding that DRN-B had lesser cooking loss than DRN-A.

\section{The effect of noodle processing method on retention of vita- $\min A$, folic acid and iron in rice noodles}

Laboratory scale processing methods were selected and set up to control each stage during studies of two different processesing methods (process A and B) on rice noodles. Overall, fortificant retention in noodles that have gone through six different stages of processing and labeled as RN-A, DRN-A, CRN-A, RN-B, DRN-B and CRN-B was studied. The retention of the fortificant in rice noodle samples was expressed as percentages of its original level in the fortified rice flour (FRF).

Vitamin A, folic acid and iron retention of rice noodle prepared by process A and B at each stage of processing are shown in Figure 4, 5 and 6, respectively. Each stage of rice noodle processing has potential effect on the retention of fortificant. The patterns of fortificant retention observed during the stages of processing for rice noodle prepared by process A and B were very similar. There were significant decreases in fortificant retention throughout the process from fortified rice flour (FRF) to the final product $(C R N)(p<0.05)$. However, the decreasing values of fortificant retention were significantly higher $(p<0.05)$ in rice noodle prepared by process A than in rice noodle prepared by process $B$. There were $16.79 \pm 2.96 \%$ and $21.91 \pm 1.35 \%$ retention of vitamin A, $12.68 \pm 2.25 \%$ and $29.06 \pm 5.66 \%$ retention of folic acid, and $89.15 \pm 0.49 \%$ and $92.68 \pm 0.48 \%$ retention of iron in CRN-A and CRN-B, respectively.

There were two stages that contributed to large losses of fortificant. First was the preparation of RN-A and RN-B from the fortified rice flour. RN-A had a significantly lower ( $\mathrm{p}$ $<0.05$ ) retention of fortificant compared to RN-B. RN-A and RN-B showed $43.15 \pm 3.17 \%$ and $69.11 \pm 1.65 \%$ retentions of vitamin A, $58.25 \pm 3.18 \%$ and $80.00 \pm 0.72 \%$ retentions of folic acid, and $96.36 \pm 0.68 \%$ and $99.52 \pm 0.35 \%$ retentions of iron, respectively. These results were consistent with the finding that the variability in fortificant retention (especially for fat soluble vitamins) was due to greater oxygen exposure during boiling than during steaming resulting in less fortificant retention in $\mathrm{RN}-\mathrm{A}$ than in RN-B. These results were also supported by the findings of previous studies which indicated that availability of oxygen during cooking affects the stability of vitamins and minerals $^{[24-26]}$.

Another factor causing less retention of fortificant in $\mathrm{RN}-\mathrm{A}$ was the leaching of the fortificant into the surrounding water during the boiling process. The result was in agreement with the findings by Watzke ${ }^{[27]}$, Dang, et al. ${ }^{[28]}$ and Lešková, et al. ${ }^{[2]}$ where it was reported that the primary mechanism leading to vitamin and mineral losses is leaching.

In the study that used Ultra Rice ${ }^{\mathrm{TM}}$ (UR) to examine retention of retinyl palmitate after cooking procedure, approximately $20 \%$ of retinyl palmitate was found in the excess water after cooking. The findings proved that leaching was the main cause of retinyl palmitate loss as a result of cooking ${ }^{[30]}$. The proportion of foliate loss from noodles during cooking has also been investigated. Bui and Small ${ }^{[31]}$ reported that boiling contributed 
to a loss of about $38 \%$ and $40 \%$ of folic acid in white salted noodles and yellow alkaline noodles, respectively, while the loss of folic acid during steaming was just $20.3 \%$ in instant noodle processing.

The other stage of rice noodle processing that caused a significant loss in the fortificant was cooking the dried rice noodles in boiling water. The losses of vitamin A when dried rice noodles were cooked in boiling water were $56.85 \%$ in DRN-A and $66.38 \%$ in DRN-B (Figure 4). This was due to the fact that vitamin A rapidly loses its activity when heated in the presence of oxygen, especially at higher temperatures. These results were in good agreement with that of Lešková, et al. ${ }^{[29]}$ who reported that boiling resulted in vitamin A losses as high as 67\%. Likewise, Sungpuag, et al. ${ }^{[32]}$ reported a $43 \%$ loss in the vitamin A content of vegetables during boiling. In addition, vitamin A loss in food products may also be caused by the presence of trace metals such as iron ${ }^{[33-37]}$. The research conducted by Solon, et al. ${ }^{[37]}$ in the Philippines revealed a substantial reduction of vitamin A to $70 \%$ after a month of storage in premix that included iron (45 mg/kg flour).

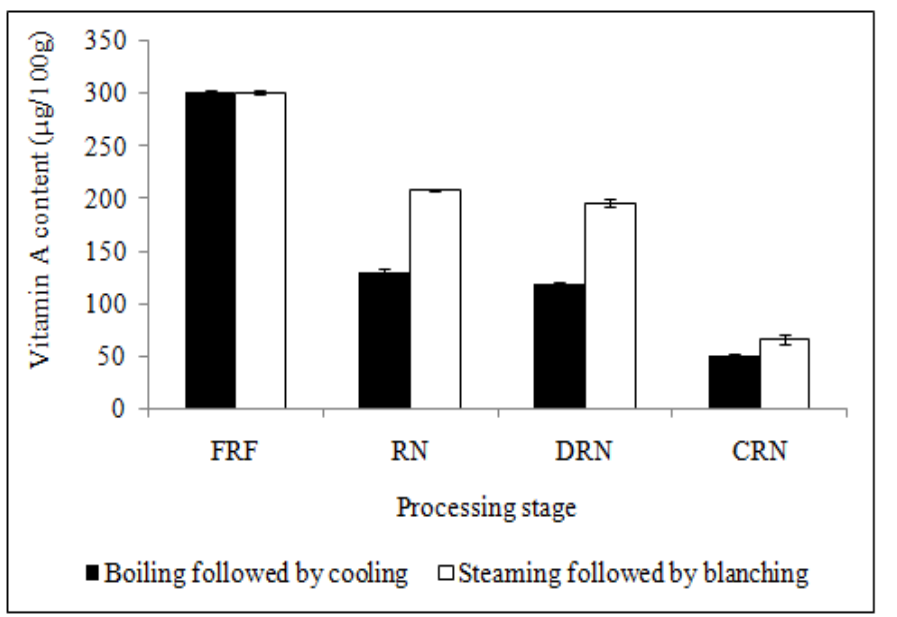

Figure 4: Vitamin A content $(\mu \mathrm{g} / 100 \mathrm{~g})$ in rice noodle prepared by two different noodle processing methods and at each stage of processing.

Data are presented as mean \pm standard deviation of triplicate determinations.

$\mathrm{FRF}=$ fortified rice flour, $\mathrm{RN}=$ fresh rice noodle, $\mathrm{DRN}=$ dried rice noodle, $\mathrm{CRN}=$ cooked rice noodle

Similarly, relatively large losses of folic acid occurred when DRN-A and DRN-B were cooked in boiling water, which were $49.95 \%$ and $38.41 \%$, respectively (Figure 5). Like many water-soluble vitamins, the loss of folic acid from rice noodle samples during processing is predominantly caused by leaching rather than by oxidation or thermal degradation. This result is supported by the findings of previous studies which reported that folate is primarily lost from leaching into the cooking water, but not due to oxidation or other degradation pathways ${ }^{[28,31,38-42]}$.

This fact is also reinforced by studies that found the sum of folate content of drained food samples and that in the drained water, after processing, to be nearly equivalent to the total folate of the raw food samples ${ }^{[28,38]}$. Similar to vitamin A, the presence of iron can also increase folic acid $\operatorname{loss}^{[30,43]}$.

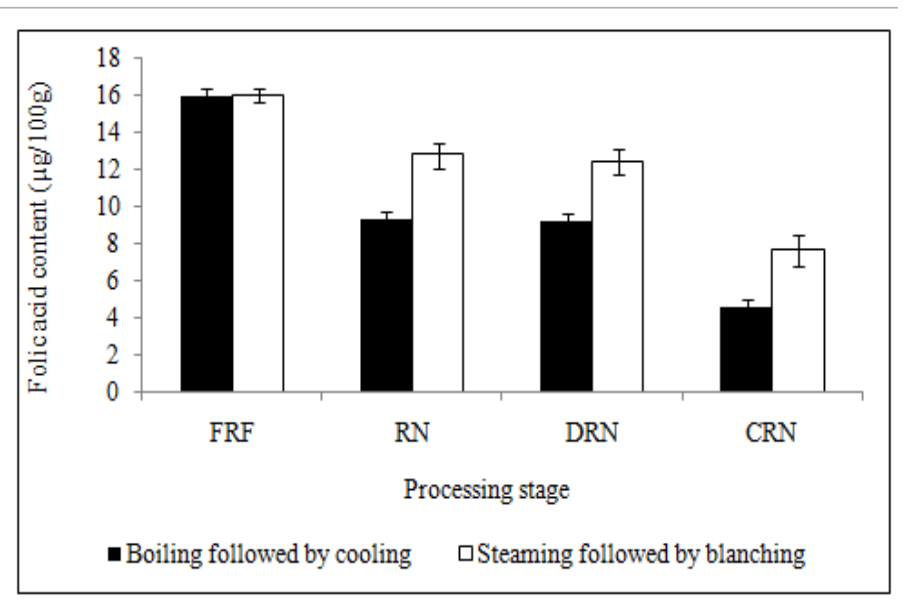

Figure 5: Folic acid content $(\mu \mathrm{g} / 100 \mathrm{~g})$ in rice noodle prepared by two different noodle processing methods and at each stage of processing.

Data are presented as mean \pm standard deviation of triplicate determinations.

$\mathrm{FRF}=$ fortified rice flour, $\mathrm{RN}=$ fresh rice noodle, $\mathrm{DRN}=$ dried rice noodle, $\mathrm{CRN}=$ cooked rice noodle.

Relatively, little loss occurred during the drying process from RN to DRN. The step of drying RN-A and RN-B for 12 hours at $40^{\circ} \mathrm{C}$ resulted in merely $8.95 \%$ and $5.70 \%$ loss of vitamin A, respectively. These results were lower than the findings of $\mathrm{O}^{\prime}$ Brien and Roberton ${ }^{[44]}$, who reported that during the processing of macaroni, oven drying for 9 to 12 hours at $50^{\circ} \mathrm{C}$ resulted in a $14 \%$ loss of vitamin A. Other study has observed a $13 \%$ loss of vitamin A after drying of long durum wheat pasta ${ }^{[45]}$. In addition, losses of folic acid were $0.32 \%$ and $2.97 \%$ during the drying of RN-A and RN-B, respectively. Bui and Small ${ }^{[31]}$ reported that drying at a temperature of $40^{\circ} \mathrm{C}$ did not affect the folate content in white salted and yellow alkaline noodles.

Compared to vitamin A and folic acid, iron was a much more stable mineral fortificant under rice noodle processing conditions in this study. However, iron was loss from the DRN-A and DRN-B samples mainly through boiling, with $6.90 \%$ and $6.45 \%$ losses, respectively (Figure 6 ). The primary mechanism of iron losses is through leaching as discussed by Watzke ${ }^{[27]}$.

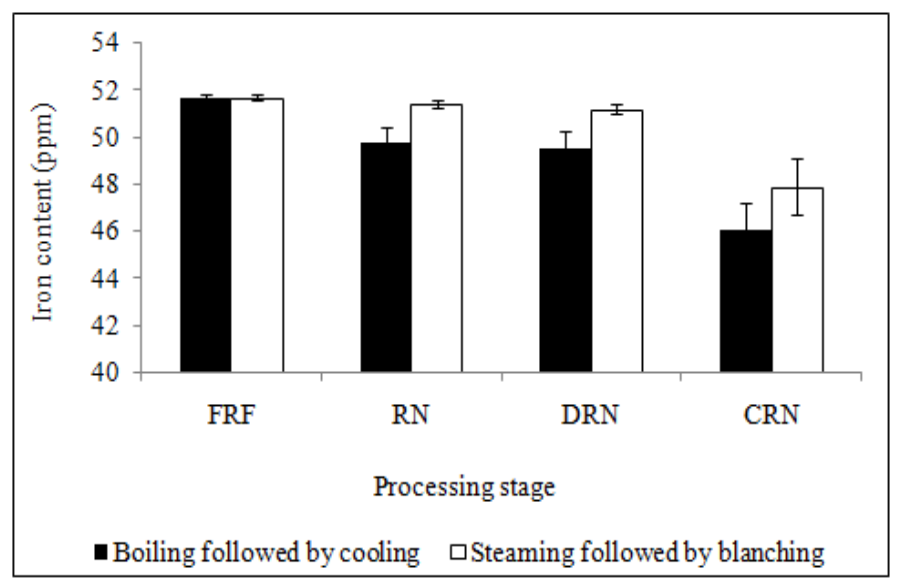

Figure 6: Iron content (ppm) in rice noodle prepared by two different noodle processing methods and at each stage of processing.

Data are presented as mean \pm standard deviation of triplicate determinations.

$\mathrm{FRF}=$ fortified rice flour, $\mathrm{RN}=$ fresh rice noodle, $\mathrm{DRN}=$ dried rice noodle, $\mathrm{CRN}=$ cooked rice noodle. 


\section{Conclusion}

Rice noodle prepared by steaming contained significantly higher amount of gelatinized starch, ash, protein and fat than rice noodle prepared by boiling. Furthermore, rice noodle prepared by steaming had better cooking and textural qualities in terms of less cooking loss, less sticky feel upon consumption, harder, springy and chewy texture, and were more preferred by sensory panelists compared to rice noodle prepared by boiling followed by cooling. The losses of vitamin A, folic acid and iron appeared to occur at each step of the rice noodle processing. However, retentions of vitamin A, folic acid and iron at each stage of the processing were significantly higher $(p<0.05)$ in steamed noodle than in boiled noodle. This was due to the regular, smooth and close structure of the steamed noodle. Of all the processing stages, the losses of vitamin A, folic acid and iron occurred substantially during cooking of the dried rice noodle. Rice noodle prepared by steaming is recommended for fortification purpose since it produced better rice noodle in terms of chemical properties, cooking and textural qualities and retentions of vitamin $\mathrm{A}$, folic acid and iron.

\section{Acknowledgement:}

The authors thank Padiberas Nasional Berhad (BERNAS) and Universiti Putra Malaysia for providing financial support for this research.

Declaration of Conflicting Interests: All authors declare no conflict of interest associated with this manuscript.

\section{References}

1. Lotfi, M., Mannar, M.G., Merx, R.J., et al. "Micronutrient Fortification of Foods, Current Practices, Research, and Opportunities: Iron, Vitamin A, Iodine". (1996) The Micronutrient Initiative (MI)/International Agriculture Center (IAC).

Others

2. Winger, R.J., König. J., House, D.A. Technological issues associated with iodine fortification of foods. (2008) Trends Food Sci Tech 19(2): 94-101.

Crossref | Others

3. Barclay, D. Multiple fortification of beverages. (1988) Food Nutr Bull 19(2): 168-171.

Pubmed | Crossref | Others

4. Rutkowski, K., Diosady, L.L. Vitamin A stability in triple fortified salt. (2006) Food Res Int 40(1): 147-152.

Crossref | Others

5. Li YO, Lam J, Diosady LL, Jankowski S. Antioxidant system for the preservation of vitamin A in Ultra Rice. (2009) Food Nutr Bull 30(1): 82-89.

Pubmed | Crossref $\mid$ Others

6. Akhtar, S., Anjum, F.M., Rehman, S.U., et al. Effect of fortification on physico-chemical and microbiological stability of whole wheat flour. (2008) Food Chem 110(1): 113-119.

Pubmed | Crossref | Others

7. Tungtrakul, P., Surojanametakul, V., Supari, R., et al. "The use of dry-milled rice flour for rice noodles production". Institute of Food Research and Product Development.

Others

8. Bhattacharya, M., Zee, S.Y., Corke, H. Physicochemical properties related to quality of rice noodles. (1999) Cereal Chem 76(6): 861-867. Crossref | Others

9. Vangsawasdi, P., Noppharat, M., Hiranyaprateep, N., et al. Relation- ship between rheological properties of rice flour and qualities of vermicelli. (2009) As J Food Ag-Ind 2(02): 102-109.

Others

10. Yoenyongbuddhagal, S., Noohorm, A. Effect of raw material preparation on rice vermicelli quality. (2002) Starch/Starke 54(11): 534-539. Crossref $\mid$ Others

11. Hormdok ,R., Noomhorm, A. Hydrothermal treatments of rice starch for improvement of rice noodle quality. (2007) LWT Food Sci Tech 40(10): 1723-1731.

Others

12. Allen, L., deBenoist, B., Dary, O., et al. Guidelines on food fortification with micronutrients. (2006) WHO and FAO.

Others

13. Hamdzah, A.R., "Model of Food Vermicelli". (1994) Mardi Publishing Comp.

14. Malahayati, N., Kharidah, M., Jamilah, B., et al. Quality and fortificant retention of rice noodles as affected by flour particle size. (2015) Cereal Chem 92(2): 211-217.

Crossref | Others

15. Malaysian Food Regulation. (1985) Malaysia Govern Printer.

16. Birch, G.G., Priestley, R.J. Degree of gelatinization of cooked rice. (1973) Die Starke 25(3): 98-100.

Crossref $\mid$ Others

17. Official Methods of Analysis of the AOAC International 16th edition. (1995) AOAC Int.

18. American Association of Cereal Chemists. (2003) Approved Methods.

19. Lawless, H.T., Heymann, H. "Sensory evaluation of food: principle and practices". (2010) Food Sci Text Series.

Crossref | Others

20. Alaburda, J., deAlmeida, A.P., Shondu, L., et al. Determination of folic acid in fortified wheat flours. (2008) J Food Comp Anal 21(4): 336-342.

\section{Crossref | Others}

21. Elliason, A.C., "Starch in food: Structure, function and applications". (2004) Woodhead Publishing Ltd

Others

22. Kim, Y., Wiesenborn, D., Lorenzen, J., et al. Suitability of edible bean and potato starches for starch noodles. (1996) Cereal Chem 73(3): 302-308.

Others

23. Juliano, B.O., Sakurai, J. "Rice: Chemistry and Technology". (1985) AACC.

24. Gregory, J.F. Chemical and nutritional aspects of folate research, analytical procedures, methods of folate synthesis, stability, and bioavailability of dietary folates. (1989) Adv Food Nutr Res 33: 1-101. Crossref | Others

25. Johnson, Q., Mannar, V., Ranum, P. Fortification handbook: Vitamin and Mineral Fortification of Wheat Flour and Maize Meal. (2004) Micronutr Initiative.

Others

26. Bo, H., "A study on elemental irons and iron compounds for food fortification", 18th International Congress of Nutrition 19-23 September. (2005) Nutrition Safari for Innovative Solutions.

27. Watzke, H.J. Impact of processing on bioavailability examples of minerals in foods. (1998) Trends Food Sci Tech 9(8-9): 320-327.

Crossref | Others

28. Dang, J., Arcot, J., Shrestha, K. Folate retention in selected processed legumes. (2000) Food Chem 68(3): 295-298.

Crossref | Others

29. Lešková, E., Kubíková, J., Kováćiková, E., et al. Vitamin losses: Retention during heat treatment and continual changes expressed by mathematical models. (2005) J Food Comp Anal 19(4): 252-276.

Crossref | Others

30. Lee, J., Hamer, M.L., Eitenmiller, R.R. Stability of retinyl palmitate during cooking and storage in rice fortified with ultra riceTM fortifica- 
tion technology. (2000) J Food Sci 65(5): 915-919.

Crossref | Others

31. Bui, L.T., Small, D.M. Folates in Asian noodles: III. Fortification, impact of processing, and enhancement of folate intakes. (2007) J Food Sci 72(5): C288-C293.

Pubmed | Crossref | Others

32. Sungpuag, P., Tangchitpianvit, S., Chittchang, U., et al. Retinol and b-carotene content of indigenous raw and home-prepared foods in Northeast Thailand. (1999) Food Chem 64(2): 163-167.

Crossref | Others

33. Pinkaew, S., Wegmuller, R., Hurrell, R. Vitamin A stability in triple fortified extruded, artificial rice grains containing iron, zinc and vitamin A. (2012) Int J Food Tech 47(10): 2212-2220.

Crossref | Others

34. Wirakartakusumah, M.A., Hariyadi, P. Technical aspect of food fortification. (1998) Food Nutr Bull 19(2): 101-108.

Crossref $\mid$ Others

35. Manan, F., Ryley, J. Effect of supplementary iron on vitamin A stability in food. (1994) Med J Islamic World Acad Sci 7(3): 181-184.

Others

36. Manan, F., Guevara, L.V., Ryley, J. The stability of all trans retinol and reactivity towards transition metals. (1991) Food Chem 40(1): 4354.

Crossref | Others

37. Solon, F.S., Sancex-Fermin, L.E., Wambango, L.S., et al. "Final report-Iron and vitamin A stability in flour and products". (1999) Nutr Center Philippines.
38. Stea, T.H., Johansson, M., Jägerstad, M., et al. Retention of folates in cooked, stored and reheats peas, broccoli and potatoes for use in modern large scale service systems. (2006) Food Chem 101(3): 10951107.

Crossref | Others

39. McKillop, D.J., Pentieve, K., Daly, D., et al. The effect of different cooking methods on folate retention in various foods that are amongst the major contributors to folate intake in the UK diet. (2002) Br J Nutr 88(6): 681-688.

Pubmed | Crossref | Others

40. Petersen, M. Influence of sous vide processing, steaming and boiling on vitamin retention and sensory quality in broccoli florets. (1993) Z Lebensm Unters Forsch197(4): 375-380.

Pubmed | Crossref | Others

41. Hawkes, J.G., Villota, R. Folates in foods: Reactivity, stability during processing, and nutritional implications. (1989) Crit Rev Food Sci Nutr 28(6): 439-538.

Pubmed | Others

42. Leichter, J., Switzer, V.P., Landymore, A.F. Effect of cooking on foliate content of vegetables. (1978) Nut Report Int18: 475-479.

43. Nisha, P., Singhal, R.S., Pandit, A.B. Degradation kinetics of folic acid in cowpea (Vigna catjang L.) during cooking. (2005) Int J Food Sci Nutr 56(6): 389-397.

Pubmed | Crossref | Others

44. O'Brien, A., Roberton, D. Technology of vitamins in foods Glasgow. (1993) Blackie Academic \& Professional.

45. Parrish, D.B., Herod, L., Ponte, J.G., et al. Recovery of vitamin A in processed foods made from fortified flours. (1980) J Food Sci 45: 1438-1439.

Others
Online ISSN: 2377-0619

Journal Title: International Journal Food and Nutritional Science Journal Short Name: Int J Food Nutr Sci
Ommega Online Publishers

E-mail: foodscience@ommegaonline.org

Website: www.ommegaonline.org 